Sammlung Metzler

Band 300 


\author{
Manfred Kammer
}

\title{
Bit um Bit
}

Wissenschaftliche Arbeiten mit dem PC

Verlag J.B. Metzler

Stuttgart - Weimar 
Die Deutsche Bibliothek - CIP-Einheitsaufnahme

Kammer, Manfred:

Bit um Bit : wissenschaftliche Arbeiten mit dem PC / Manfred Kammer.

- Stuttgart ; Weimar : Metzler, 1997

(Sammlung Metzler ; Bd. 300)

ISBN 978-3-476-10300-0

\author{
ISBN 978-3-476-10300-0 \\ ISBN 978-3-476-03996-5 (eBook) \\ DOI 10.1007/978-3-476-03996-5 \\ ISSN 0558-3667
}

\title{
SM 300
}

Dieses Werk einschließlich aller seiner Teile ist urheberrechtlich geschützt. Jede Verwertung außerhalb der engen Grenzen des Urheberrechtsgesetzes ist ohne Zustimmung des Verlages unzulässig und strafbar. Das gilt insbesondere für Vervielfältigungen, Übersetzungen, Mikroverfilmungen und die Einspeicherung und Verarbeitung in elektronischen Systemen.

(C) 1997 Springer-Verlag GmbH Deutschland

Ursprünglich erschienen bei J.B. Metzlersche Verlagsbuchhandlung und Carl Ernst Poeschel Verlag GmbH in Stuttgart 1997 


\section{Inhalt}

1 Einleitung $\ldots \ldots \ldots \ldots \ldots \ldots \ldots \ldots \ldots \ldots \ldots \ldots \ldots \ldots$

2 Materialsammlung und -ordnung .............. 8

2.1 Verwaltung bibliographischer Daten............. 8

Verschlagwortung $\ldots \ldots \ldots \ldots \ldots \ldots \ldots \ldots \ldots, \ldots \ldots$

Zitierregeln ....................... 10

2.1.1 Bibliographieren mit dem PC ................ 12

2.1.2 Bibliographien und Datenbanken............. 13

2.2 Verwaltung von Exzerpten, Zitaten, Materialien...... 17

2.2.1 Verwaltung von Materialien in Textverarbeitungsprogrammen ............. 18

2.2.2 Verwaltung von Materialien in Datenbankprogrammen .. 21

3 Die Gestaltung des Manuskripts ............... 24

3.1 Von der Konzeption zur Gliederung.............. 25

Gliederung mit Hilfe der Gliederungsansicht . . . . . . . . 27

3.2 Das Layout des Textes........................ 32

3.2 .1 Zeichenformatierung........................ 33

Schriftart/Schriftgröße................. 34

Auszeichnungen ...................... 35

3.2.2 Absatzformatierung ........................ 37

Zeilenabstand ....................... 38

Ausrichtung des Absatzes . . . . . . . . . . . . 38

Einrückungen...................... 39

Leerräume . . . . . . . . . . . . . . . . 40

3.2.3 Standard-Formatvorlagen $\ldots \ldots \ldots \ldots \ldots \ldots \ldots, 40$

Formatvorlage "Standard«(absatz) . . . . . . . . . 41

Formatvorlage »Überschrift" ................ 42

Fußnoten .................... 47

3.2.4 Benutzerdefinierte Formate ................... 51

Hervorhebung von Zitaten .............. 51

Literaturangaben in Bibliographien........... 55

Zeichenformate: Autornamen, Buchtitcl etc. . ...... 56

3.2.5 Allgemeine Hilfen ....................... 58

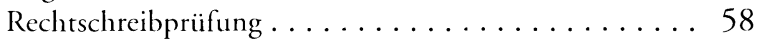

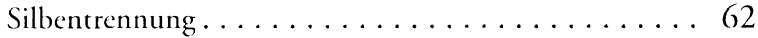

Sprachwahl ....................... 63

Manuskriptansichten................... 64 
3.3 Das Layout des Manuskriptes . . . . . . . . . . 67

3.3 .1 Titelei .............................. 67

3.3 .2 Seitenlayout ....................... 71

Reproduktionsfähige Vorlagen . . . . . . . . . 73

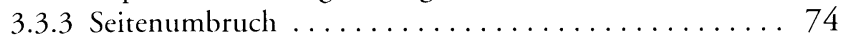

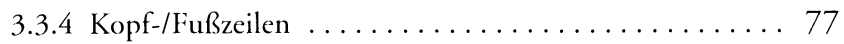

Kopfzeilen . . ............... 80

3.4 Weitere Gestaltungselemente des Manuskripttextes ... 83

3.4.1 Aufzählungen/ Listen . . . . ............. 83

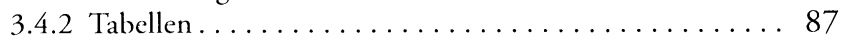

3.4 .3 Rahmen. . . . . . . . . . . . . . . 91

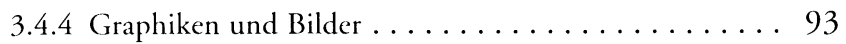

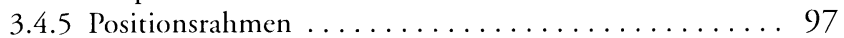

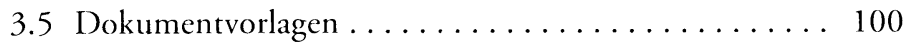

4 Hilfen bei der Erstellung von Manuskripten . . . . . . 105

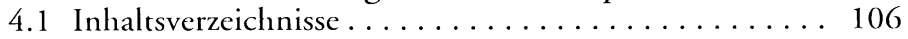

4.2 Querverweise .................... 108

4.3 Erstellung von Registern und Verzeichnissen ....... 113

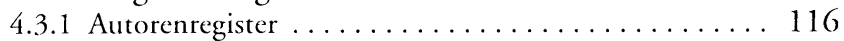

4.3.2 Sachregister ...................... 118

4.3.3 Verzeichnisse von Tabellen, Abbildungen, etc. ...... 123

4.4 Bibliographien ................... 124

4.4.1 Die Anordnung der Literatur in der Bibliographic . . . 125

4.4.2 Erstellen von Bibliographien

aus Datenbankprogrammen ............. 126

5 Elektronische Suchhilfen . . . . . . . . . . . . . . . 129

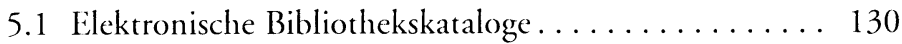

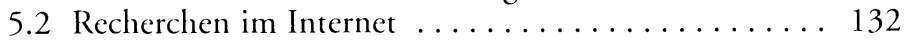

5.2 .1 Zugang zu Bibliotheken................ 134

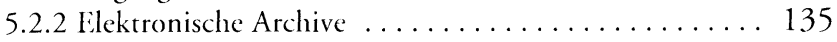

5.2 .3 Informationsorte . . . . . . . . . . . . . 136

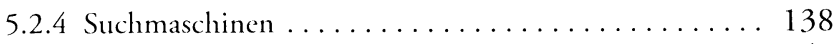

5.3 Zitieren von Internet-Dokumenten $\ldots \ldots \ldots \ldots 141$

Abbildungsverzeichnis . . . . . . . . . . . . . . 144

Literaturhinweise .................... 145 